Bangl. J. Vet. Med. (2006). 4 (2): 79-85

\title{
SEROPREVALENCE AND PATHOLOGICAL STUDY OF SALMONELLA INFECTIONS IN LAYER CHICKENS AND ISOLATION AND IDENTIFICATION OF CAUSAL AGENTS
}

\author{
M. M. Islam, M. G. Haider, E. H. Chowdhury, M. Kamruzzaman ${ }^{1}$ and M. M. Hossain*
}

Department of Pathology, Faculty of Veterinary Science, Bangladesh Agricultural University, Mymensingh,

Bangladesh, *Corresponding author: mokbul@royalten.net.bd; mmhossain@yahoo.com.au

\begin{abstract}
The present research work was conducted to study about the seroprevalence and pathology of Salmonella infections in layer chickens of Dhaka and Gazipur regions of Bangladesh and to isolate and characterize Salmonellae from layer chickens during the period from January to May 2006. The used materials were blood sample, cloacal and liver swabs from live and dead birds respectively, and visceral organs (liver, lungs, spleen and intestine). The used methods were serum plate agglutination (SPA) test; necropsy and histopathology; cultural, morphological and biochemical test. The overall seroprevalence was $43.4 \%$. During necropsy, congested and enlarged liver with focal necrosis, haemorrhagic and discoloured ovary with stalk formation and mild haemorrhagic to catarrhal enteritis in intestine were detected. Microscopically, the liver showed congestion, focal necrosis with multifocal infiltration of histiocytes in liver parenchyma. In ovum, infiltration of leukocytes, bacterial colony, RE cell proliferation and fibrinoid necrosis were recorded. The intestinal mucosa exhibited infiltration of mononuclear cells in mucosa, submucosa as well as muscularis mucosa. A total of 33 (21.02\%) Salmonellae from live and dead birds were isolated. The isolation rate of Salmonellae was higher in seronegative (31.6\%) group than seropositive (3.2\%) group. Out of 33 Salmonella isolates, 25 were S. pullorum, 3 were S. gallinarum and the rest 5 were motile Salmonellae. The isolates obtained in the study may be investigated for serotyping, pathogenesis study, antibiogram and vaccine production in future.
\end{abstract}

Key words: Seroprevalence, histopathology, isolation, identification, Salmonella, chickens

\section{INTRODUCTION}

Salmonellosis in poultry causes heavy economic loss through mortality and reduced production (Khan et al., 1998). With great expansion of poultry rearing and farming, pullorum disease and fowl typhoid have become wide spread problem in Bangladesh (Rahman et al., 1979). In Bangladesh, the Salmonella infections in chicks and layer chickens must be evaluated for effective control measures of the diseases. Therefore, the present study was undertaken to determine the seroprevalence and pathological study of Salmonella infections in layer chickens and to isolate and characterize Salmonellae from those chickens.

\section{MATERIALS AND METHODS}

The present research work was undertaken in the Department of Pathology, Bangladesh Agricultural University, Mymensingh, Bangladesh. Samples were collected from different layer farms of Dhaka and Gazipur regions of Bangladesh in the period of January to May 2006.

\section{Seroprevalence study}

\section{Sample collection and preparation}

A total of 362 blood samples (Table 1) were collected from layer chickens of Dhaka and Gazipur regions and where no Salmonella vaccine was used previously. Blood of about $1 \mathrm{ml}$ from each bird was collected aseptically, allowed for clotting in the syringe and then sera were separated and centrifuged (where necessary) at $1000 \mathrm{rpm}$ for 10 minutes for clarification. During the study according to age and status of growth, the birds were divided into 4 groups: starter (up to $8 \mathrm{wks}$ ), grower/pre-layer (9-20 wks), layer (21-60 wks) and post-layer (> $60 \mathrm{wks}$ ).

Present address: ${ }^{1}$ Bio-Lab, H\#10, R\# 3/A, Uttara-9, Dhaka-1230.

Copyright $@ 2006$ Bangladesh Society for Veterinary Medicine

All rights reserved 1729-7893/0097/06 


\section{Serum plate agglutination (SPA) test}

Standard Salmonella pullorum (Nobilis ${ }^{\circledR}$ SP, Intervet International, Holland) antigen was used for SPA test. Antigen of $0.02 \mathrm{ml}$ and chicken sera of $0.02 \mathrm{ml}$ were placed side by side with a micropipette on ceramic tiles and mixed thoroughly by stirring with tooth pick followed by rocking. Results of positive reaction (clumping) on mixing (Plate 1) were read within 2 minutes.

\section{Pathological study}

\section{Gross pathology}

A total number of 37 dead layer chickens was examined to detect Salmonella infections. At necropsy, gross tissue changes were observed and recorded carefully and representative tissue samples (liver, lungs, spleen \& intestine) containing lesions were preserved in $10 \%$ buffered formalin for histopathological studies.

\section{Histopathology}

The tissues were trimmed, washed, processed in ascending grades of alcohol, cleared in chloroform, embedded in paraffin, sectioned using a microtome and stained with hematoxylin and eosin (H\&E) stain as per standard procedure (Luna, 1968). Photomicrography was taken using photomicrographic camera (Olympus PM-C 35 Model).

\section{Isolation and identification of Salmonellae}

\section{Collection of samples}

A total of 120 cloacal swabs (63 from seronegative and 57 from seropositive birds) were collected after seroprevalence study. Along with these 120 samples, 37 liver swabs were collected from the birds at necropsy.

\section{Culture}

All the samples were collected on tetrathionate broth. Then subculture was performed on different selective and enriched media of Salmonella such as Salmonella -Shigella (SS) agar, lysine iron agar (LIA), triple sugar iron (TSI) agar, and brilliant green agar (BGA) to get pure culture and to study cultural characteristics (Cown, 1985; Merchant and Packer, 1967; OIE, 2004).

\section{Morphological characterization}

The representative Salmonellae colonies on BGA were characterized microscopically using Gram's stain according to the method described by Merchant and Packer (1967). The motility test was performed according to the method described by Cown (1985) to differentiate motile Salmonellae from the non-motile.

\section{Biochemical test}

Five basic sugars such as dextrose, sucrose, lactose, maltose, and mannitol were used for sugar fermentation test. Several types of biochemical tests such as TSI agar slant reaction, methyl red (MR) test, Voges Proskuer (VP) test, indole test and dulcitol fermentation test were also performed in this study according to the methods described by Cown (1985), Merchant and Packer (1967) and OIE (2004).

\section{RESULTS AND DISCUSSION}

\section{Seroprevalence study}

In this study, the overall seroprevalence of Salmonellosis was recorded as 43.4\% (Table 1). Yang et al. (1996) reported relatively similar findings (39.02\%). Ashenafi et al. (2003) and Habib-ur-Rahman et al. (2003) reported $64.2 \%$ and $63.5 \%$ respectively, that was much higher than that of the present study. The variation of seroprevalence might be speculated due to geographical variation or difference of management. But the present finding (43.4\%) in commercial farms was higher than the seroprevalence (23.46\%) recorded by Sikder et al. (2005) in local chickens. The difference with Sikder et al. (2005) was corresponded with the findings of Jha et al. (1995) and Robinson et al. (2000), who recorded seroprevalence rate higher in commercial flock than local chickens. 
Table 1. Seroprevalence of Salmonella infections in different groups of chickens

\begin{tabular}{|lccc|}
\hline Groups & $\begin{array}{l}\text { No. of sera } \\
\text { samples tested }\end{array}$ & $\begin{array}{l}\text { No. of seropositive } \\
\text { samples }\end{array}$ & Seroprevalence \\
\hline Starter (up to 8 wks) & 024 & 001 & $04.2 \%$ \\
Grower/pre-layer (9 - 20 wks) & 094 & 018 & $19.1 \%$ \\
Layer (21 - 60 wks) & 196 & 103 & $52.6 \%$ \\
Post-layer (> 60 wks) & 048 & 035 & $72.9 \%$ \\
\hline Total & 362 & 157 & $43.4 \%$ \\
\hline
\end{tabular}

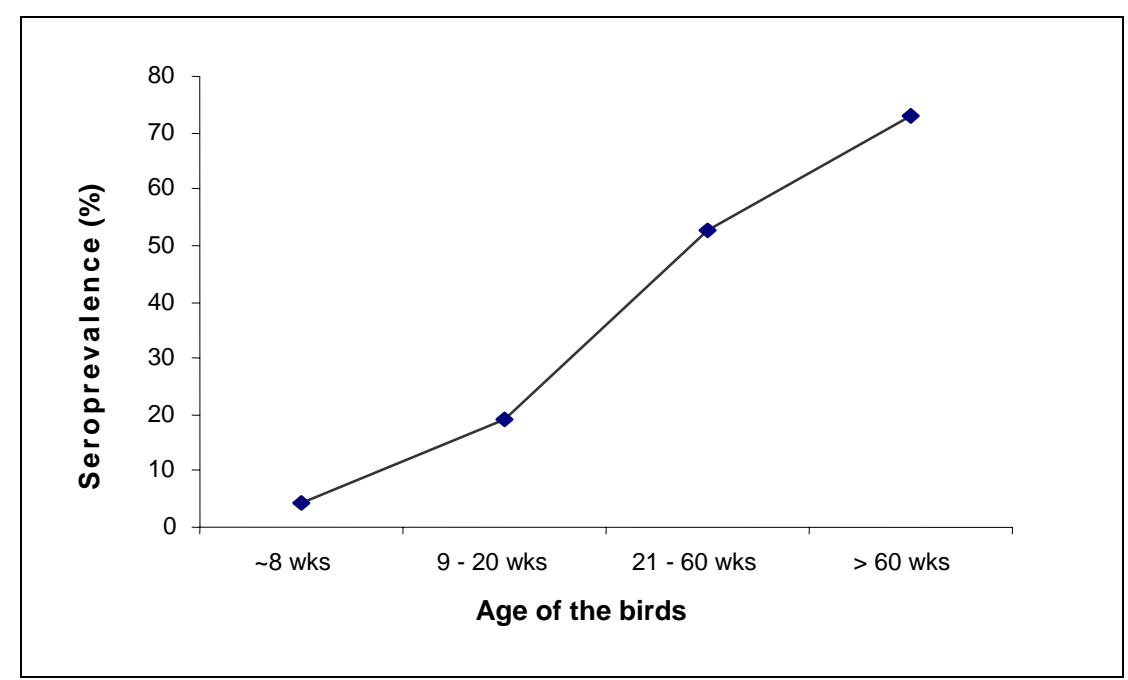

Fig. 1. Seroprevalence of Salmonella infections in terms of age of the birds

It was found that seroprevalence increased with the increase of age of the birds (Table 1 and Fig.1). This findings corresponded with the reports of Sikder et al. (2005) and Truong and Tieuquang (2003).

\section{Pathological study}

\section{Gross pathology}

Enlarged and congested liver with focal necrosis; haemorrhagic and discoloured ovary with stalk formation (Plate 2) and mild haemorrhagic to catarrhal enteritis in intestine and caecum were recorded during necropsy. These types of necropsy findings were supported by Calnek et al. (1997), Chauhan and Roy (1996), Syed-Habib-ur-Rahman et al. (2004), Hossain et al. (2003) and Khan et al. (1998).

\section{Histopathology}

Microscopically, the liver showed congestion, focal necrosis with multifocal infiltration of histiocytes in liver parenchyma (Plate 3). In ovum, infiltration of leukocyte, bacterial colony, RE cell proliferation and fibrinoid necrosis were recorded (Plate 4). The spleen showed severe congestion, mild hyperplasia of RE cells and fibrinoid necrosis. The intestinal and caecal mucosa exhibited infiltration of mononuclear cells in the mucosa and submucosa (Plate 5). These types of histological lesions were supported for Salmonella infection by different investigators (Calnek et al., 1997; Chauhan and Roy, 1996; Syed-Habib-ur-Rahman et al., 2004; Refsum et al., 2002). 


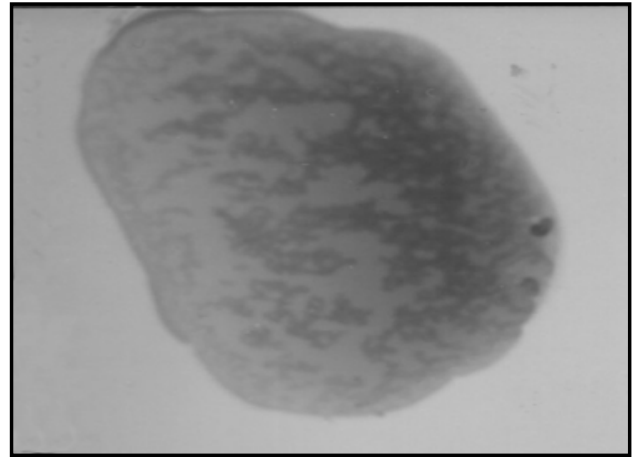

Plate 1 . Serum plate agglutination test (positive reaction).

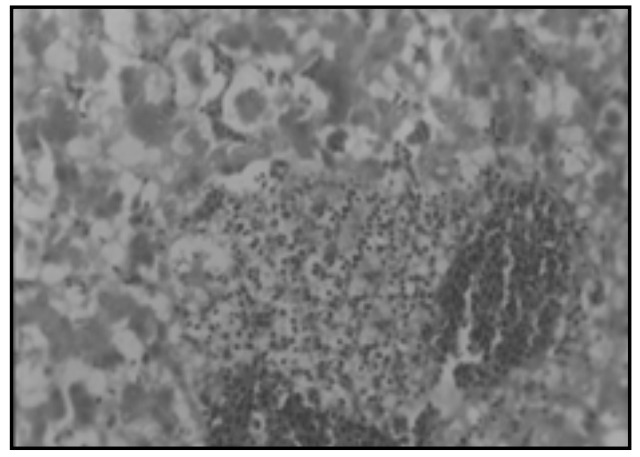

Plate 3. Histopathology of Salmonella infected liver showing congested blood vessel, infiltration of heterophils, lymphocyte and histiocytes around the blood vessel $(\mathrm{H} \& \mathrm{E}$ stain, X 184).

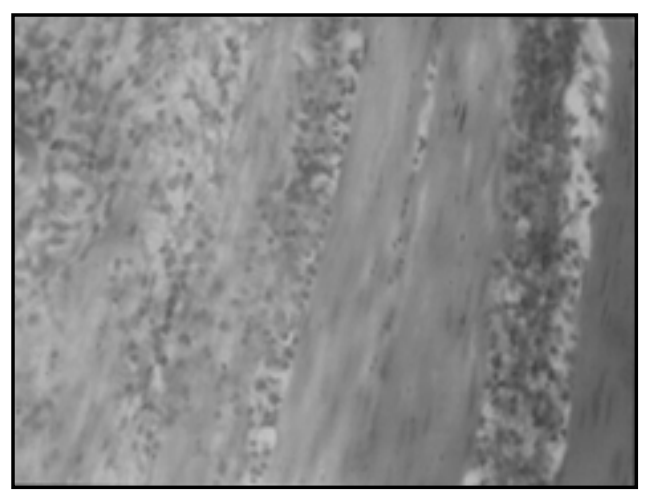

Plate 5. Histopathology of Salmonella infected caecum shows severe infiltration of heterophils, lymphocytes and plasma cells in mucosa and submucosa as well as in muscularis mucosa (H \& E stain, X 186).

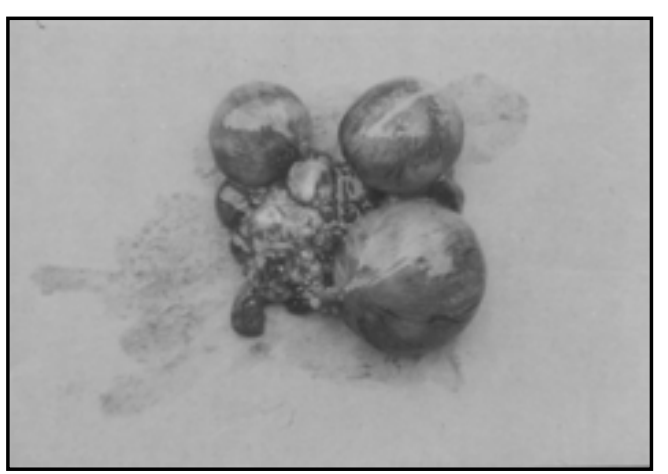

Plate 2. Ovarian follicles of Salmonella infected chicken showing haemorrhagic lesion, discolouration and stalk (peduncle) formation.

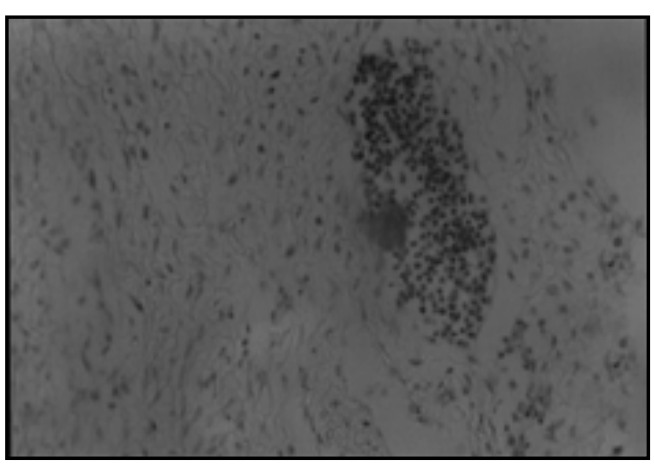

Plate 4. Histopathology of Salmonella infected ovary showing infiltration of leukocyte, congestion with pink colour bacterial colonies in blood vessel (H \& E stain, X 184).

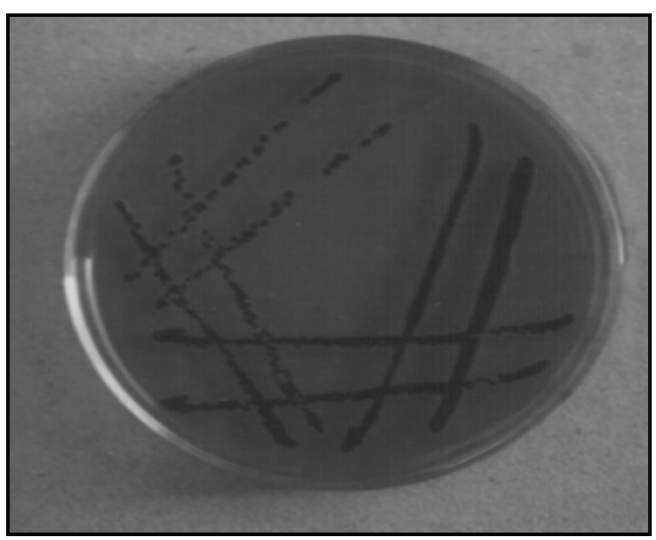

Plate 6. Culture of Salmonellae in TSI agar shows black colour colonies. 
Salmonella infections in layer chickens

\section{Isolation and characterization of Salmonellae}

The colony characters of Salmonellae, in SS agar was whitish or slight grayish colonies with dark central spot reflecting production of hydrogen sulfide on the media; in LIA, slight blackish colour colonies; in TSI agar, black colour colonies (Plate 6) and in BGA, pink white colour colonies which corresponds with Perez et al. (2004), Sharma and Katok (1996), Yuno et al. (1995) and Old (1990). On the basis of colony characters, from 120 cloacal swabs and 37 liver swabs, 33 were identified as Salmonella spp (Table 2). In Gram's staining, the morphology of the isolated bacteria was small rod shape, gram negative, single or paired in arrangement which is supported by Freeman (1985).

Table 2. Salmonella isolated from live and dead birds

\begin{tabular}{|llll|}
\hline Source of sample & No. of sample & No. of isolates & Prevalence \\
\hline Live bird (Cloacal swab) & 120 & 20 & $16.7 \%$ \\
Dead bird (liver swab) & 37 & 13 & $35.1 \%$ \\
\hline Total & 157 & 33 & $21.02 \%$ \\
\hline
\end{tabular}

The overall cultural prevalence in live and dead birds was recorded 21.02\% (Table 2). The cultural prevalence in live birds was $16.7 \%$, whereas in dead birds, it was $35.1 \%$. It should be noted that the live birds were not clinically diseased; on the other hand the dead birds were due to case fatality. The higher cultural prevalence in dead bird than live bird was related with the report of Haider et al. (2003).

A total of 18 isolates (31.6\%) was found from 57 seronegative birds and 2 (3.2\%) from 63 seropositive birds (Table 3). The rate of isolation from seropositive birds was very lower than that of the seronegative birds. Higher rate of isolation from seronegative birds than seropositive birds were also found by Lee et al. (2001) and Hoque et al. (1996).

Table 3. Correlation between seroprevalence and Salmonella isolates

\begin{tabular}{|lcc|}
\hline Agglutination test result group & Cloacal swab collected & Salmonella isolated \\
\hline Seronegative & 57 & $18(31.6 \%)$ \\
Seropositive & 63 & $2(3.2 \%)$ \\
\hline Total & 120 & $20(16.7 \%)$ \\
\hline
\end{tabular}

Table 4. Biochemical activities of different isolates of Salmonellae

\begin{tabular}{|c|c|c|c|c|c|c|c|c|c|c|c|}
\hline \multicolumn{5}{|c|}{ Carbohydrate fermentation test } & \multirow[t]{2}{*}{ Indole } & \multirow[t]{2}{*}{ MR } & \multirow[t]{2}{*}{ VP } & \multirow[t]{2}{*}{ Motility } & \multirow[t]{2}{*}{ Dulcitol } & \multirow{2}{*}{$\begin{array}{l}\text { Name of the } \\
\text { isolated bacteria }\end{array}$} & \multirow{2}{*}{$\begin{array}{l}\text { No. of the } \\
\text { isolated bacteria }\end{array}$} \\
\hline Glu & Man & Lac & Suc & Mal & & & & & & & \\
\hline A & AG & - & - & - & - & + & - & - & - & S. pullorum & 25 \\
\hline AG & A & - & - & A & - & + & - & - & AG & S. gallinarum & 3 \\
\hline AG & AG & - & - & AG & - & + & - & + & AG & $\begin{array}{l}\text { Other motile } \\
\text { salmonellae }\end{array}$ & 5 \\
\hline
\end{tabular}

Glu = Glusose, Man = Mannitol, Lac = Lactose, Suc $=$ Sucrose, Mal $=$ Maltose, MR = Methyl red test, VP = Voges-proskauer test, $A G=$ Acid and Gas, A=Acid, $+=$ Positive, $-=$ Negative. 
Motility test is fundamental basis for the detection of motile and non-motile Salmonellae. Non-motile organisms were considered to be either S. pullorum or S. gallinarum. The motile organisms were considered as other species of Salmonella (OIE, 2004; Calnek et al., 1997; Chauhan and Roy, 1996). In the present study, 28 isolates were non-motile and 5 were motile (Table 4).

The ability or inability of Salmonellae to ferment different carbohydrates are used as fundamental basis for their identification (Freeman, 1985). In the present study, all isolates fermented glucose and mannitol but did not ferment lactose and sucrose. Some Salmonellae fermented maltose, some did not. All of the isolates were MR positive but VP and indole negative (Table 4). These findings were previously suggested by a number of scientists (Merchant and Packer, 1967; Buxton and Fraser, 1977; Sujatha et al., 2003; Khan et al., 1998).

The dulcitol fermentation test is performed to confirm the differentiation of S. pullorum and S. gallinarum (Robinson et al., 2000). In the present study, 3 out of 28 isolated nonmotile Salmonellae, fermented dulcitol (Table 4). On the basis of this test, these three isolated bacteria were grouped into Salmonella gallinarum (OIE, 2004). Other 25 nonmotile isolates, produced acid and gas in glucose and mannitol but did not ferment maltose (or fermentation occurred in later stage) and dulcitol, so considered as S. pullorum (Shivaprasad, 1997 and OIE Manual, 2004). Rest five isolates were motile and fermented glucose, maltose, mannitol and dulcitol. So these motile Salmonellae were identified as paratyphoid Salmonellae. Among the total (33) isolates, 3 (9.1\%) were Salmonella gallinarum, 25 (75.8\%) were Salmonella pullorum and other 5 (15.2\%) were paratyphoid Salmonella. These findings of isolation were also supported by Girao et al. (1985), Hoque et al. (1996).

However, for useful application of the present research findings further studies should be focused on serotyping and molecular characterization and identification of immunogenic variation and development of vaccine with isolated Salmonellae.

\section{REFERENCES}

1. Ashenafi H, Shetu Y and Oldemeskel M (2003). Identification of major infections of local chickens of Central Ethiopia. Bulletin of Animal Health and Production in Africa 51:95-101.

2. Buxton A and Fraser G (1977). Animal Microbiology. Vol. 1. Blackwell Scientific Publications, Oxford, London, Edinburg, Melbourne.

3. Calnek BW, Barnes HJ, Beard CW, McDougald LR and Saif YM (1997). Diseases of Poultry. 10 $0^{\text {th }}$ ed. Iowa State University Press, Ames, USA.

4. Chauhan HVS and Roy S (1996). Poultry diseases, diagnosis and treatment. $2^{\text {nd }}$ ed. New age international (P) ltd. publishers, New Delhi, India.

5. Cown ST (1985). Cown and Steel's Manual for the Identification of Medical Bacteria. $2^{\text {nd }}$ edn. Cambridge University Press, Cambridge, UK.

6. Freeman BA (1985). Burrow’s Text Book of Microbiology. $22^{\text {nd }}$ edn. W. B. Saunders Company, London, UK.

7. Girao FGF, Nogueira RHG, Oliverira RL, Ferreira HBC and Oliveriara RL (1985). Isolation of Salmonella from feed stuffs, rations and samples collected from chicks with various health problems. Arquivo Brasileiro de Medicina Veterinaria e Zootecnia 37: 249-256.

8. Habib-ur-Rahman S, Sirzanin, Hamayun K, Saleem K, Nazir A. and Bhatti WM (2003). Incidence and gross pathology of salmonellosis in chicken in Hyderabad. Journal of Association of Veterinary Advances. 2: 581-584.

9. Haider MG, Hossain MG, Hossain MS, Chowdhury EH, Das PM and Hossain MM (2003). Isolation and characterization of enterobacteria associated with health and disease in Sonali chickens. Bangladesh Journal of Veterinary Medicine. 2: 15-21.

10. Hoque MM, Biswas HR and Rahman L (1996). Isolation, identification and production of Salmonella pullorum coloured antigen in Bangladesh for the rapid whole blood test. Asian Australian Journal of Animal Science 10: 141-146.

11. Hossain MA, Aalbaek B, Christensen JP, Elisabeth H , Islam MA and Pankaj K (2003). Observations on experimental infection of Salmonella gallinarum in Fayoumi and Hyline layer chickens in Bangladesh. Progressive Agriculture 14: 85-89.

12. Jha, V. C., Thakur, R. P., Chand, T. K. and Yadav, J. N. 1995. Prevalence of salmonellosis in chickens in the Eastern Nepal. Veteterinary Bulletin 65: 7.

13. Khan AHMNA, Bari ASM, Islam MR, Das PM and Ali MY (1998). Pullorum disease in semi mature chickens and its experimental pathology. Bangladesh Veterinary Journal 32: 124-128.

14. Lee YJ, Kang MS, Woo YK, Mo IP and Tak RB (2001). Competitive exclusion against Salmonella gallinarum of Salmonella enteritidis infected chickens. Journal of Veterinary Science 2:33-36.

15. Luna LG (1968). Manual of Histologic Staining Methods of the Armed Forces Institute of Pathology. $3^{\text {rd }}$ edn. McGraw Hill Book Co., New York, USA. 
16. Merchant IA and Packer RA (1967). Veterinary Bacteriology and Virology. $7^{\text {th }}$ ed. The Iowa State University Press, Ames, Iowa, USA.

17. OIE (Office International des Epizootic) manual (2004). Salmonellosis and fowl typhoid \& pullorum diseases. In: OIE Guide-2. Manual of Diagnostic tests and vaccines for terrestrial Animals.

18. Old DC (1990). Salmonella. In: Topley \& Wilson's Principles of Bacteriology, Virology and Immunity. $8^{\text {th }}$ edn. Parker, M. T. and Duerden, B. I. (ed.). Vol. 2 Systematic Bacteriology. Edward Arnold. A division of Hodder \& Stoughton, London, UK.

19. Perez C, Rivera S, Pirela A, Rincon H, Mavarez Y and Roman R (2004). Isolation of Salmonella in poultry carcasses and evaluation of the effectiveness of different enrichment and selective media. Revista Cientifica Facultad Ciencias Veterinarias Universidad del Zulia 14: 177-185.

20. Rahman MM, Chowdhury TIMF, Rahman MM and Hossain WIMA (1979). Survillance of Salmonella \& Escherichia organisms in poultry feed. Bangladesh Veterinary Journal 15: 59-62.

21. Refsum T, Handeland K, Baggesen DL, Holstad G and Kapperud G (2002). Salmonellae in avian wild life in Norway from 1969 to 2000. Veterinary Bulletin 73: 360.

22. Robinson H, Mdegela MGS, Yongolo U, Minga M and Johin E (2000). Molecular epidemiology of Salmonella gallinarum in chickens in Tanzania. Avian Pathology 29: 457-463.

23. Sharma M and Katock RC (1996). Deadly outbreak in chicks owing to Salmonella typhimurium. Indian Journal of Poultry Science 31: 60-62.

24. Shivaprasad HL (1997). Pullorum disease and fowl typhoid. In calnek, B.W. Jarnes H.J. Beard, C.W., McDougald, L. R and Saif Y.M (Edn). Diseases of Poultry. $10^{\text {th }}$ (edn) Ames, IA: Iowa State University Press.

25. Sikder AJ, Islam MA, Rahman MM and Rahman MB (2005). Seroprevalence of Salmonella and Mycoplasma gallisepticum infection in the six model breeder farms at Patuakhali district of Bangladesh. International Journal of Poultry Science 4: 905-910.

26. Sujatha K, Dhanalakshmi K and Rao AS (2003). Isolation and characterisation of Salmonella gallinarum from chicken. Indian Veterinary Journal 80: 473-474.

27. Syed-Habib-ur-Rahman, Khan MS, Hamayun K, Nazir A and Bhatii WM (2004). Incidence and gross pathology of Salmonella gallinarum infection in chicken. Journal of Animal and Veterinary Advances 3: 175-178.

28. Truong Q and Tieuquang AN (2003). Prevalence of Salmonella gallinarum pullorum infection in the Luong Phuong chickens reared in the household sector. Khoa-Hoc-Ky-Thuat-Thu-Y-Veterinary-Sciences-and-Techniques 10: 15-19.

29. Yuno MML, Terzolo HR, Fernandez HD, Malena RC and Altuna ME (1995). Evaluation of selective culture media for isolation of Salmonella from poultry. Revista Argentina de Microbiologia 27: 57-69. 